\title{
Determination of Ethanol Content in Medicated Syrups: A Comparison among Distillation, Titration and GC Methods
}

\author{
ANANADA KUDALE ${ }^{1}$, KHUDBUDIN MULANI $^{1}$, RAGHUNATH TOCHE ${ }^{2}$, \\ SHOBHA BORHADE ${ }^{3}$, BALASAHEB DAUNDKAR $^{1}$ and BHAUSAHEB MORE ${ }^{1 *}$ \\ ${ }^{1}$ Directorate of Forensic Science Laboratories, Kalina, Santacruz (E), \\ Mumbai-400098, M. S. India \\ ${ }^{2}$ Dept. of Chemistry, KTHM College, Nashik-422002, M. S., India \\ ${ }^{3}$ S. M. B. S. T. College, Sangamner-422605, Dist.-Ahmed Nagar, M. S., India \\ bhaumore1@gmail.com
}

Received 24 November 2015 / Accepted 10 December 2015

\begin{abstract}
Determination of ethanol content in medicated syrups was studied. We analysed ten medicated syrups namely; Aswins Balant kadha, Aswins Balkadu, Aswins Balant kadha, Aswins Paripathadi Kadha, Sandu Draksharishta, Franco-Indian P Dexorange hematinic Syrup, Raptakos Brett \& Co. Elixir Neogadine, Virbac Animal Health Brotone Vet, Heptoglobin, Chereyl Laboratories Minoxidil topical solution. The ethanol content in the medicated syrups was determined by simple distillation, titration and GS-HS method. After distillation, ethanol content was analysed by Anton Paar Alcohol analyser. Modified oxidation-diffusion method was used as titration method for determination of ethanol concentration. A new GC-HS method was developed for analysis of ethanol and all samples were analysed directly without dilution except Chereyl Laboratories Minoxidil topical solution. The result shows that, ethanol content from all three methods gives comparable values and those are within the labelled claim.
\end{abstract}

Keywords: Forensic sciences, Ethanol content, Medicated syrups, Distillation, Titration, GC-HS

\section{Introduction}

The determination of ethanol in alcoholic beverages is an important task for economic reasons in relation to the taxes imposed on alcohol. The higher the ethanol contents in alcoholic beverages, higher the tax. In this context, a simple precise and accurate method for quantitative analysis of ethanol content is needed as the standard method. The ethanol content in alcoholic beverages is in the range ${ }^{1}$ of 7 to $50 \%$.

In pharmaceutical product, the ethanol content depends on formulation and varies in the wide range from fraction to tens of percent ${ }^{1-3}$. For making liquid formulation like syrups, solutions, suspension and emulsion, the highest ethanol concentration is used. The paediatric 
patients who are very often unable to swallow the solid preparation like capsules and tablets, these types of preparations are most useful. Now a days nearly $80 \%$ of paediatric medicines are produced as liquids and it contains ethanol content is in the range ${ }^{4}$ from 2.3 to $20 \%$.

The prenatal exposure to ethanol may also have effect on child development. It includes hyperactivity and attention problems, learning and memory deficits and also problems with social and emotional development ${ }^{5,6}$. Due to these harmful effects, the American academy of paediatrics has set the limit for the inclusion of ethanol in OTC paediatric formulation as 5\% $(\mathrm{v} / \mathrm{v})^{2}$. In consequences, a simple and accurate method for the determination of ethanol is needed.

Currently, literature reports that, quantitative determination of ethanol can be performed by several methods. It includes, refractive index $\operatorname{method}^{7}$, dichromate oxidation spectroscopy method $^{7,8}$, HPLC ${ }^{9,10}$, gas chromatography ${ }^{3,11,12}$, enzymatic method ${ }^{13-15}$, beer analyser ${ }^{7}$, flow injection analysis ${ }^{16,17}$, capillary $\mathrm{GC}^{12}$ and static head space $\mathrm{GC}^{18}$. In this study, the determination of ethanol content in medicated syrups was done by three methods namely simple distillation, titration and GC-HS and results were compared among themselves.

\section{Experimental}

Potassium dichromate and potassium iodide were procured from Sisco research lab Mumbai, India. Sodium thiosulfate and starch were purchased from Thomus Baker India. Ethanol and n-propyl alcohol (HPLC grade $99.9 \%$ purity) procured from Merck India. Ten syrup samples including Aswins Balantkadha, Aswins Balkadu, Aswins Balantkadha, Aswins Paripathadi Kadha, Sandu Draksharishta, Franco-Indian P Dexorange hematinic Syrup, Elixir Neogadine, Virbac Animal Health Brotone Vet, Heptoglobin, Chereyl Laboratories Minoxidil topical solution were used.

The modified oxidation-diffusion method was used as titration method ${ }^{19}$ and titration were performed by using digital VIT-Lab titration flask. In titration method, $5 \mathrm{~mL}$ of $0.05 \mathrm{~N}$ potassium dichromate was taken in round bottom flask, to this $5 \mathrm{~mL}$ of concentrated sulfuric acid was added slowly and cooled to room temperature (i.e. oxidizing reaction mixture). Syrup samples $(0.5 \mathrm{~mL})$ were pipetted out in another glass bulb. A vacuum was applied to the round bottom flask using three way knobs whose one end contains oxidizing reaction mixture. The glass bulb was attached to the other end of the three way knob and immerses the bulb in boiling water bath to vaporize ethyl alcohol. The three way knob turned to bring the entire vapour in contact with oxidizing reaction mixture. The flask was then kept for 3-4 minutes and then $20 \mathrm{~mL}$ of distilled water was added to it.

To the flask $5 \mathrm{~mL}$ of $10 \%$ potassium iodide solution was added to react unreacted dichromate solution and liberate free iodine. Liberated free iodine was titrated with $0.05 \mathrm{~N}$ sodium thiosulfate solutions by using starch as an indicator. The end point was faint blue to colorless solution. The titration was done in duplicate. After distillation, samples were analysed by Anton Paar alcohol analyser. Perkin Elmer Clarus-500 GC-HS with FID detector was used for determination of ethanol content in medicated syrups. The instrument parameters are given in the Table 1.

The polar Elite wax column $(30 \times 0.32)$ was used for determination of ethanol content in medicated syrups because no sample pre-treatment procedures are required for this column. The calibration of GC was done with the ethanol concentration range $20-400 \mathrm{mg} / 100 \mathrm{~mL}$. In this study we used $n$-propanol $(0.1 \%)$ as internal standard for quantitative determination of ethanol content in medicated syrups. When concentration of ethanol ( $\mathrm{X}$ axis) plotted against peak area $(\mathrm{Y}$ axis) a linear regression equation $(\mathrm{Y}=0.5987 \mathrm{X})$ was generated and the correlation coefficient $\mathrm{R}^{2}$ is 0.9994 as show in Figure 1. 
Table 1. GC instrument parameters

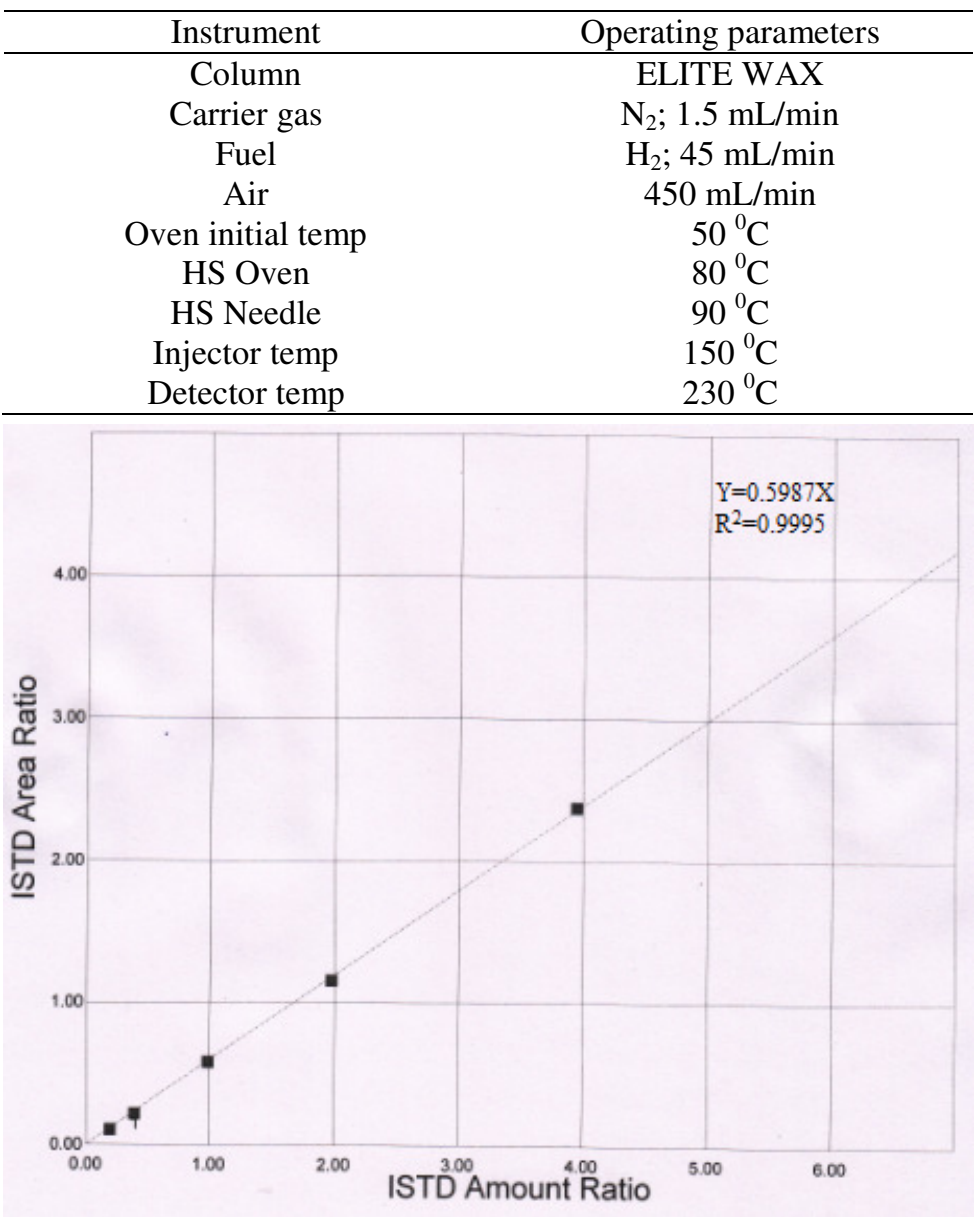

Figure 1. Calibration plot

\section{Results and Discussion}

The quantitative determination of ethanol content in medicated syrups was studied by three different methods and results shown in the Table 2. The sample of medicated syrups and their distillates were analysed in duplicate. The flow rates of $\mathrm{H}_{2}$ and air were set as $45 \mathrm{~mL} / \mathrm{min}$ and $450 \mathrm{~mL} / \mathrm{min}$ respectively. The $230{ }^{\circ} \mathrm{C}$ and $90{ }^{\circ} \mathrm{C}$ temperature were set for FID and injection port respectively. Nitrogen gas was used as carrier gas and its flow rate was $1.5 \mathrm{~mL} / \mathrm{min}$.

Table 2. Ethanol content determined by three methods

\begin{tabular}{llcccc}
\hline S. & \multirow{2}{*}{ Name of syrup } & \multicolumn{4}{c}{ Alcohol \% v/v } \\
\cline { 3 - 6 } No. & & Labelled & Distillation & Titration & GC-HS \\
\hline 1 & Aswins Balant Kadha & $4.30 \%$ & 4.31 & 7.13 & 7.47 \\
2 & Aswins Balkadu & NMT $^{\# 1} 12 \%$ & 5.06 & 7.48 & 7.78 \\
3 & Aswins Balant Kadha & $6.20 \%$ & 6.17 & 7.24 & 7.78 \\
\hline
\end{tabular}




\begin{tabular}{|c|c|c|c|c|c|}
\hline 4 & Ashwins Paripathadi Kadha & $5.90 \%$ & 5.83 & 7.08 & 7.24 \\
\hline 5 & Sandu Draksharishta & NMT $9.5 \%$ & 7.46 & 8.22 & 8.74 \\
\hline 6 & $\begin{array}{l}\text { Franco-Indian P.Dexorange, } \\
\text { Hematinic syrup }\end{array}$ & $5.5 \%$ & 5.10 & 4.31 & 4.89 \\
\hline 7 & $\begin{array}{l}\text { Raptakos, Brett \& co., Elixir } \\
\text { Neogadine }\end{array}$ & $6 \%$ & 5.88 & 5.88 & 6.03 \\
\hline 8 & Virbac Animal Health, Brotone Vet. & $9.4 \%$ & 9.43 & 6.18 & 6.64 \\
\hline 9 & Raptakos, Brett \& co.,Hepatoglobin & $2.3 \%$ & 2.35 & 1.38 & 1.48 \\
\hline 10 & $\begin{array}{l}\text { Chereyl Lboratories, Minoxidil } \\
\text { topical solution }\end{array}$ & $40 \%$ & 39.74 & 41.92 & 42.8 \\
\hline
\end{tabular}

${ }^{\#} N M T$-Not more than

When applying the GC condition, the standard sample of ethanol was run having concentration 20,40,100, 200 and $400 \mathrm{mg} / \mathrm{mL}$. The retention time of ethanol and internal standard were 3.76 and 5.70 respectively as shown in Figure 2.

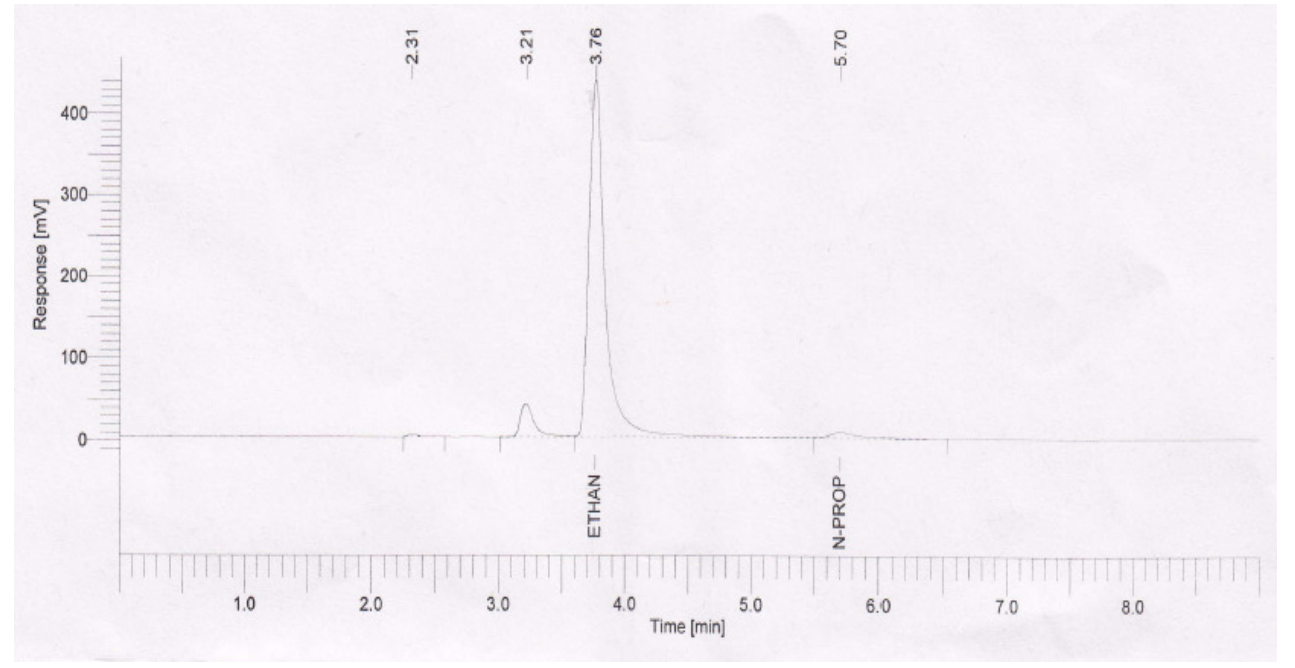

Figure 2. Retention time of ethanol and IS

To obtain calibration graph peak area of the sample plotted against concentration of the ethanol. It was found that, calibration curve was linear over concentration range up to $400 \mathrm{mg} / \mathrm{mL}$ as shown in Figure 1 hence this calibration method was found to be accurate and precise and used for quantitative determination of alcohol content.

This GC method was compare with dichromate method and distillation method for quantitative determination of ethanol content in medicated syrups. Ethanol content measure by these three methods has comparable value and those are in good agreement with labelled values. There are no significant difference between these three methods was observed. It indicates that, oxidation-diffusion method can apply for determination of ethanol content in syrups samples because titration methods is very simple, low cost and can avoid use of costly instrument.

\section{Conclusion}

In this work we determine the ethanol concentration of ten medicated syrups by three different methods. Ethanol content measured by these three methods has comparable value 
and those are in good agreement with labelled values. Thus present study provides method of choice for simple to well equipped laboratory for the determination of ethanol content in medicated syrup.

\section{References}

1. Dangor C M and Veltman A M, Afr Med J., 1985, 68(3), 172.

2. American Academy of Pediatrics, Committeeon Drugs: Pediatrics, 1984, 73, 405-407.

3. Fiocchi A, Riva E and Giovannini M, Nutr Res., 1999, 19(3), 373-379; DOI:10.1016/S0271-5317(99)00004-4

4. Kulkarni M L, Sureshkumar C and Venkataramana V, Br Med J., 1993, 307(6907), 773.

5. Larroque B, Kaminski M, Dehaene P, Subtil D, Delfosse M J and Querleu D, Am J Public Health, 1995, 85(12), 1654-1661.

6. Jacobson J L and Jacobson S W, Alcohol Res Health, 2002, 26(4), 282-286.

7. AOAC Official Method of Analysis Wines-In Official Methods of Analysis of AOAC International, $15^{\text {th }}$ Edition, 1990, 739-750.

8. Caputi A Jr, Ueda M and Brown T, Am J Enol Vitic., 1968, 19(3), 160-165.

9. $\quad$ Kupina S A, Am J Enol Vitic., 1984, 35(2), 59-62.

10. Martin E, Iadaresta V, Giacometti J C and Vogel J, Mitt Geb Lebensmittelunter Hyg., 1986, 77, 528-534.

11. Antonelli A, Vitic Enol Sci., 1994, 49, 165-167.

12. Naviglio D, Romano R and Attanasio G, Italian Food Bever Technol., 2001, 24, 19-21.

13. Jones A W, J Anal Toxicol., 1995, 19(3), 169-174; DOI:10.1093/jat/19.3.169

14. McCloskey L P and Replogle L L, Am J Enol Vitic., 1974, 25(4), 194-197.

15. Mason M, J Am Soc Brew Chem., 1983, 41, 89-90.

16. Mattos I L, Sartini R P, Zagatto E A G, Reis B F and Gine M F, Anal Sci., 1998, 14, 1005-1008; DOI:10.2116/analsci.14.1005.

17. Wagner K, Bilitewski U and Schmid R D, Microchem J., 1992, 45(2), 114-120; DOI:10.1016/0026-265X(92)90002-K

18. Huzar E and Wodnicka A, Acta Poloniac Pharmaceutica Drug Research, 2013, 70(1), 41-49.

19. Mahal H S, Ana Chem., 1959, 31(11), 1908-1909, DOI:10.1021/ac60155a075 